\title{
Communications
}

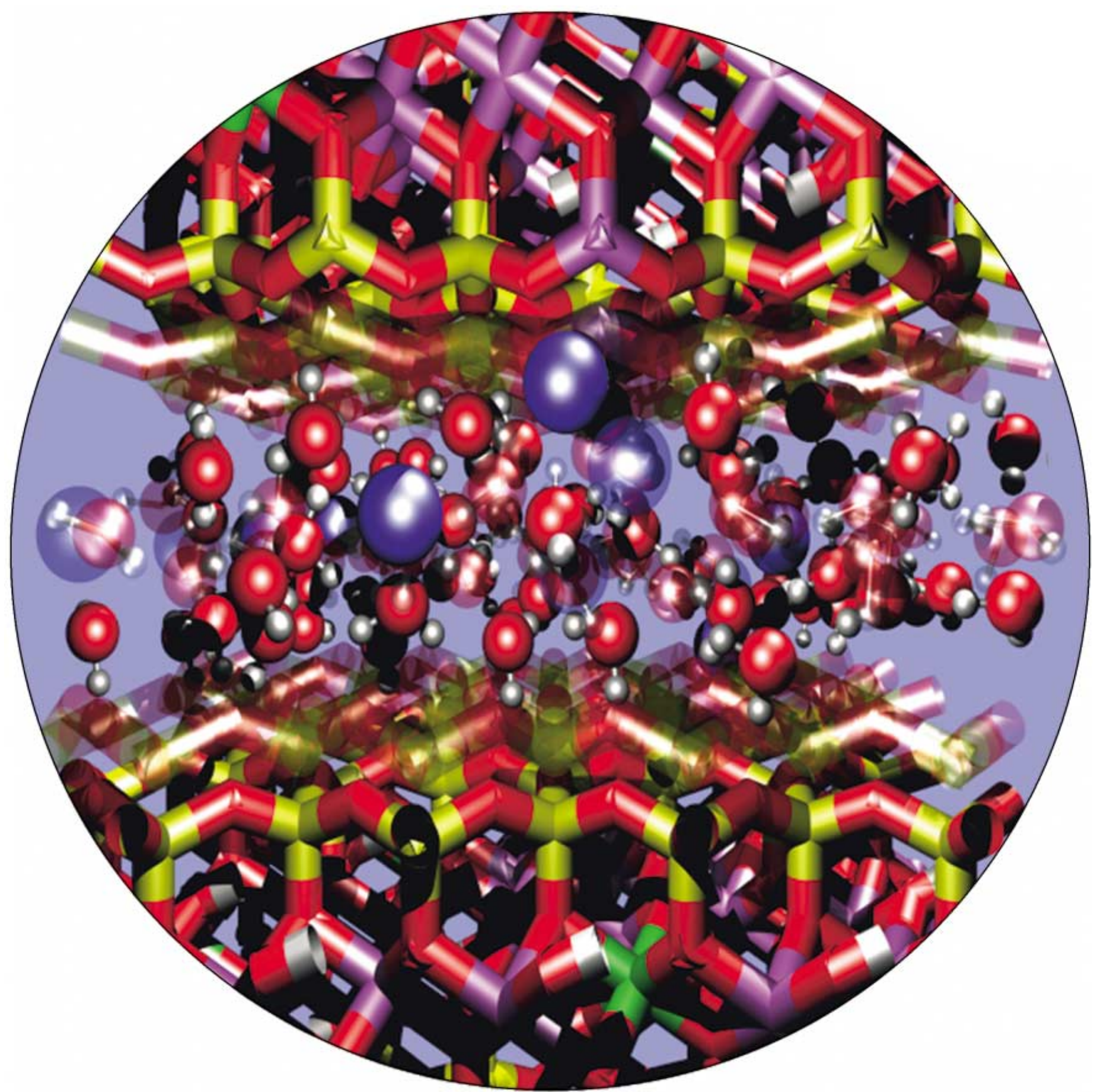

Swelling and shrinking in clay minerals, such as the NA-montmorillonite shown, occurs in a stepwise fashion and by different pathways. Through simulations it has been shown that a free-energy barrier separating stable layered hydrates is the cause of this hysteresis. For more information see the Communication by T. J. Tambach et al. on the following page. 


\section{A Molecular Mechanism of Hysteresis in Clay Swelling**}

\section{Tim J. Tambach,* Peter G. Bolhuis, and Berend Smit}

Clay minerals are an important class of materials because they are extensively present in many soils and sediments. ${ }^{[1]}$ They are also used in many very different applications, such as construction material, additives to mud drilling, or catalysis. ${ }^{[2]}$ In these applications it is important to control the swelling properties of clay minerals. For example, the extreme swelling capacity of these materials can cause severe difficulties for construction on clay soils. ${ }^{[3]}$ Depending on their structure, certain clay minerals are capable of swelling as a function of the relative humidity, ${ }^{[4-9]}$ salt concentration, ${ }^{[10,11]}$ or temperature. ${ }^{[12,13]}$ From a fundamental point of view the swelling behavior is only partially understood. Experiments showed that swelling proceeds stepwise, forming layers of water molecules (layered hydrates) between the clay-mineral platelets. $^{[5-13]}$ Interestingly, this swelling shows hysteresis; the adsorption and swelling proceeds differently from desorption and shrinking. ${ }^{[4,6,8-10,12-14]}$ In the literature there is little consensus about the molecular origin of this hysteresis. ${ }^{[15]}$ Explanations are given in terms of structural rearrangements in the clay ${ }^{[8,16]}$ or changes in interactions between layers upon expansion or contraction. ${ }^{[13,17]}$ In this work, we use molecular simulation to study the mechanism of $\mathrm{Na}$-montmorillonite swelling hysteresis in detail. In particular, we demonstrate that this hysteresis has a thermodynamic origin and its molecular mechanism is a free-energy barrier separating the transition between stable layered hydrates. Our simulations also predict how swelling hysteresis depends on the external pressure.

Before discussing the mechanism of hysteresis in detail, we should establish that we can reproduce the experimental system sufficiently accurately. In our simulations we use the TIP4P water model and we describe the clay-water and clayclay interactions with Lennard-Jones and Coulomb interactions. We used clay mineral structures modeling Arizona ${ }^{[18]}$ and Wyoming ${ }^{[19]}$ montmorillonite, which have a different layer charge and swelling properties. ${ }^{[7]}$ To mimic the experimental setup, we allow the number of water molecules to vary in our simulations. For a given clay mineral layer spacing,

[*] Dr. T. J. Tambach, Dr. P. G. Bolhuis, Prof. Dr. B. Smit

Department of Chemical Engineering

University of Amsterdam

Nieuwe Achtergracht 166, 1018 WV Amsterdam (The Netherlands) Fax: (+31) 20-525-5604

E-mail: tambach@science.uva.nl

[***] This work is supported by FOM (Stichting Fundamenteel Onderzoek der Materie) and by the Netherlands Research Council for Chemical Sciences (NWO-CW) through PIONIER. We thank Dr. E. J. M. Hensen, Dr. E. S. Boek, and Prof. D. L. Bish for their contributions.

() Supporting information for this article is available on the WWW under http://www.angewandte.org or from the author. water corresponding to a particular water (partial) pressure. Special techniques are essential for these simulations to ensure that we can sample the high-density water phase correctly. Details on the simulation techniques and models can be found in the Supporting Information and in references [18] and [19]. In Table 1 we compare the stable states

Table 1: Comparison of the simulation results with experimental measurements for Wyoming (W) and Arizona (A) montmorillonite. ${ }^{[a]}$

\begin{tabular}{llcll}
\hline & \multicolumn{2}{c}{ Basal spacing $[\AA]$} & \multicolumn{2}{c}{ Water content $\left[\mathrm{gg}^{-1}\right]$} \\
\hline & Sim. & Exp. & Sim. & Exp. \\
1-layer (W) & 12.75 & $12.49^{[b]}$ & 0.122 & $0.11-0.13^{[b]}$ \\
2-layer (W) & 15.50 & $15.55^{[b]}$ & 0.231 & $0.19^{[b]}$ \\
1-layer (A) & 12.75 & $12.5^{[c]}$ & 0.135 & - \\
2-layer (A) & 15.00 & $15.3^{[\mathrm{c}]}$ & 0.232 & - \\
\hline
\end{tabular}

[a] The stable one-layer $(\mathrm{RH}=25 \%)$ and two-layer $(\mathrm{RH}=67 \%)$ states correspond to those basal spacings for which the free energy has a (local) minimum at the given external pressure (1 atm). [b] From Cases et al. ${ }^{[9]}[\mathrm{c}]$ From Chipera et al. ${ }^{[6]}$

obtained from our molecular simulations with the experimentally observed stable states for Arizona ${ }^{[6]}$ and Wyoming ${ }^{[9]}$ $\mathrm{Na}$-montmorillonite. These results show that our water-clay model can accurately reproduce both the basal spacing as well as the water content. The computed basal spacings are also in agreement with computer simulations. ${ }^{[1,19,20]}$

Experimentally, adsorption and desorption experiments can be carried out by changing the temperature or the relative humidity $(\mathrm{RH})$, related to the water chemical potential $(\mu)$. Figure 1 shows the free energy as a function of the basal

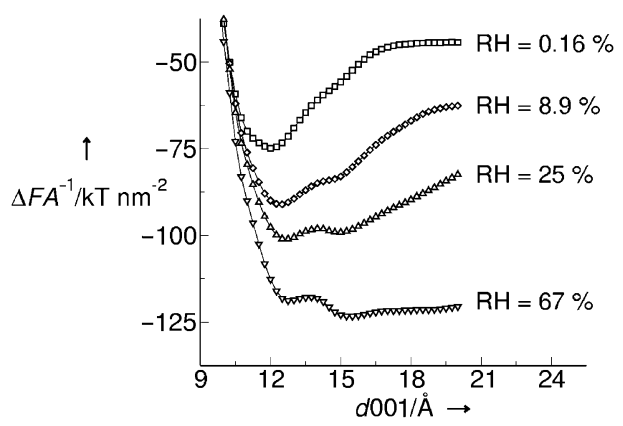

Figure 1. Free energy $(\Delta F)$ per unit area of the clay layers $(A)$ of the Wyoming clay-water system as a function of the basal spacing ( $d 001)$ for various values of the $\mathrm{RH}$; as a reference we used the free energy of the dehydrated clay.

spacing of the clay mineral for various values of the relative humidity. The minima in the free-energy curves are related to the packing of the water molecules and therefore indicate layer formation between the clay-mineral platelets. At low relative humidity the one-layer state has the lowest free energy. If we increase the humidity, we observe that above a particular value of the relative humidity the two-layer state has the lowest free energy. Figure 2 shows the relative free energies of the stable states as a function of the relative humidity or, equivalently, the chemical potential. Without 

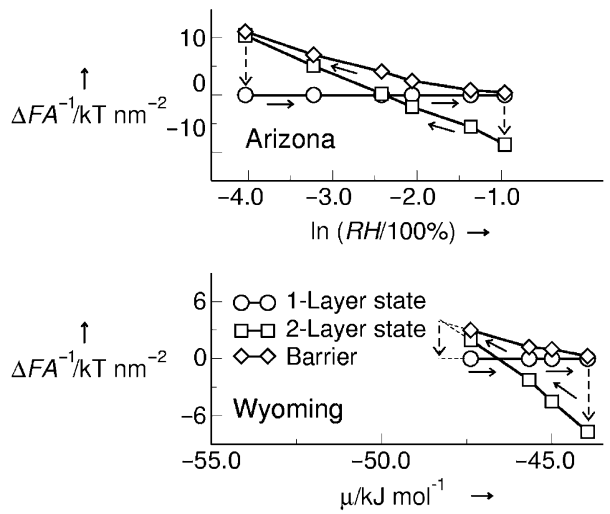

Figure 2. $\Delta F$ of the two-layer hydrate and the free-energy barrier separating the stable states, relative to the free energy of the one-layer hydrate. For both Arizona and Wyoming montmorillonte, the free energy is shown per $A$, as a function of the chemical potential $(\mu)$ or, equivalently, the $\mathrm{RH}$. We used the experimental equation of state to convert the chemical potential to the relative humidity. The arrows indicate the hysteresis loop. Note that outside the hysteresis loop there is only one minimum and hence the relative free energies of the two-layer hydrate and the barrier cannot be defined.

hysteresis the system would jump from the one-layer to the two-layer state and vice versa at exactly the point where the two free energies are equal. However, Figure 1 also shows that the two stable states are separated by a maximum in the free energy. To swell or shrink, the system has to overcome the free-energy barrier. For swelling, this barrier is the difference between free energies of the maximum and the one-layer stable state, and for desorption this barrier is the difference between the free energies of the maximum and the two-layer stable state. Figure 2 shows that one has to decrease or increase the relative humidity significantly beyond the point of equal free energies before these barriers disappear.

According to our simulations, the free-energy barrier alone explains the existence of hysteresis in an adsorption/ desorption experiment. The free-energy barrier we calculate in our simulation is the barrier of swelling the entire clay system at once. Since this barrier is proportional to the total area of the clay-mineral platelets, the total free-energy barrier should be very large and, in a perfect crystal, the system can only jump if this barrier has (almost) disappeared. This fact is also observed when we simulate a swelling experiment; the jumps in the swelling and shrinking curves correspond to those relative humidity values for which the barrier has disappeared. ${ }^{[14]}$ Figure 2 also shows that the hysteresis loop depends on the type of clay mineral. Compared to Wyoming, the hysteresis loop for Arizona montmorillonite shifts to lower values of relative humidity.

Our simulations therefore do not support the hypothesis that clay swelling hysteresis is caused by irreversible changes in the clay mineral structure ${ }^{[8,16]}$ However, this does not imply that defects or local changes in the structure of the clay mineral have no influence on the hysteresis. In our mechanism defects can induce "nucleation" sites from which the new stable state "grows" into the system and therefore result in a hysteresis loop that is significantly smaller than one would observe in an ideal system.
Relatively little is known about the swelling behavior of clay minerals at high external pressures, representing conditions in sedimentary basins. ${ }^{[21]}$ We can use our simulations to investigate the effect of external pressure on the hysteresis loop. Figure 3 indicates that one can also observe a hysteresis

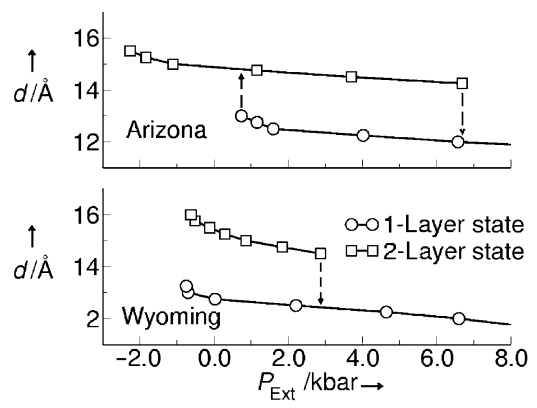

Figure 3. Basal spacing ( $d 001)$ of the one- and two-layer hydrate as a function of the external pressure $\left(P_{\text {Ext }}\right)$ for Wyoming and Arizona montmorillonte. In these simulations we impose the temperature $(T=298 \mathrm{~K})$ and the chemical potential $\left(\mu=-45.0 \mathrm{~kJ} \mathrm{~mol}^{-1}\right)$ or, equivalently, the relative humidity $(\mathrm{RH}=67 \%)$; the external pressure is an additional thermodynamic variable imposed on the system.

loop by changing the external pressure. By increasing the external pressure, one can induce desorption by changing the clay mineral from a two-layer into a one-layer state. Interestingly, because of hysteresis, a subsequent decrease in pressure does not recover the original two-layer hydrate for Wyoming montmorillonite. It would be interesting if experiments can confirm swelling hysteresis as a function of the external pressure.

In summary, our simulations show that clay swelling hysteresis has a thermodynamic origin. The molecular mechanism for this hysteresis is a free-energy barrier, which separates stable layered hydrates. This barrier determines the swelling and shrinking of clay minerals. We also show that applying external pressure on clay minerals can induce hysteresis.

Received: December 23, 2003 [Z53612]

Keywords: clay minerals - computer chemistry - minerals . molecular dynamics - thermodynamics

[1] C. Durand, T. Forsans, C. Ruffet, A. Onaisi, A. Audibert, Rev. Inst. Fr. Pet. 1995, 50, 187-218; W. F. Bleam, Rev. Geophys. 1993, $31,51-73$.

[2] M. M. Hanczyc, S. M. Fujikawa, J. W. Szostak, Science 2003, 302, $618-622$.

[3] H.v. Olphen, An Introduction to Clay Colloid Chemistry, 2nd ed., John Wiley \& Sons, New York, 1977, p. 318.

[4] R. W. Mooney, A. G. Keenan, L. A. Wood, J. Am. Chem. Soc. 1952, 74, 1367-1371.

[5] R. W. Mooney, A. G. Keenan, L. A. Wood, J. Am. Chem. Soc. 1952, 74, 1371-1374; S. B. Hendricks, R. A. Nelson, L. T. Alexander, J. Am. Chem. Soc. 1940, 62, 1457-1464; F. H. Gillery, Am. Mineral. 1959, 44, 806-818; I. Bérend, J. M. Cases, M. François, J.-P. Uriot, L. Michot, A. Masion, F. Thomas, Clays 
Clay Miner. 1995, 43, 324-336; K. Tamura, H. Yamada, H. Nakazawa, Clays Clay Miner. 2000, 48, 400-404.

[6] S. J. Chipera, J. W. Carey, D. L. Bish in Advances in X-Ray Analysis, Vol. 39 (Eds.: J. V. Gilfrich, R. Jenkins, R. L. Snyder), Plenum, New York, 1997, p. 713-722.

[7] T. Sato, T. Watanabe, R. Otsuka, Clays Clay Miner. 1992, 40, $103-113$.

[8] H. v. Olphen, J. Colloid Sci. 1965, 20, 822-837; M. H. Fu, Z. Z. Zhang, P. F. Low, Clays Clay Miner. 1990, 38, 485-492.

[9] J. M. Cases, I. Bérend, G. Besson, M. François, J.-P. Uriot, F. Thomas, J. E. Poirier, Langmuir 1992, 8, 2730-2739.

[10] K. Norrish, Discuss. Faraday Soc. 1954, 18, 120-134; B. G. Laffer, A. M. Posner, J. P. Quirk, Clay Miner. 1966, 6, 311-321.

[11] P. G. Slade, J. P. Quirk, K. Norrish, Clays Clay Miner. 1991, 39 , 234-238; P. G. Slade, J. P. Quirk, J. Colloid Interface Sci. 1991, $144,18-26$.

[12] G. J. d. Silva, J. O. Fossum, E. DiMasi, K. J. Måløy, Phys. Rev. B 2003, 67, 094114; N. Wada, D. R. Hines, S. P. Ahrenkiel, Phys. Rev. B 1990, 41, 12895-12902.

[13] J. A. Kittrick, Soil Sci. Soc. Am. Proc. 1969, 33, 217-222.

[14] E. J. M. Hensen, B. Smit, J. Phys. Chem. B 2002, 106, 12664 12667.

[15] D. A. Laird, C. Shang, M. L. Thompson, J. Colloid Interface Sci. 1995, 171, 240-245.

[16] D. H. Everett in The solid-gas interface (Ed.: E. A. Flood), Marcel Dekker, New York, 1967, p. 1055-1113; E. S. Boek, P. V. Coveney, N. T. Skipper, Langmuir 1995, 11, 4629-4631.

[17] W. Hirst, Discuss. Faraday Soc. 1947, 3, 22-28.

[18] E. J. M. Hensen, T. J. Tambach, A. Bliek, B. Smit, J. Chem. Phys. 2001, 115, 3322-3329.

[19] E. S. Boek, P. V. Coveney, N. T. Skipper, J. Am. Chem. Soc. 1995 117, 12608-12617.

[20] R. M. Shroll, D. E. Smith, J. Chem. Phys. 1999, 111, 9025-9033; M. Chávez-Páez, K. Van Workum, L. dePablo, J. J. dePablo, J. Chem. Phys. 2001, 114, 1405-1413.

[21] V. A. Colten, Clays Clay Miner. 1986, 34, 385-389; L. de Pablo, M. L. Chávez, A. K. Sum, J. J. De Pablo, J. Chem. Phys. 2004, 120, 939-946; H. v. Olphen in Clays and Clay Minerals, Proceedings of the 11th National Conference, Ottawa, Ontario, 1962 (Ed.: W. F. Bradley), Pergamon, New York, 1963, p. 178187. 